DOI 10.37882/2223-2982.2021.10-2.18

\title{
ФРАКТАЛЬНОЕ САМОПОДОБИЕ В ТЕКСТАХ ОРИГИНАЛА И ПЕРЕВОДА
}

\section{FRACTAL SELF-SIMILARITY IN THE ORIGINAL AND TRANSLATED TEXTS}

Z. Safina

Summary: The article deals with fractal self-similarity in original and translated texts. Literary texts reveal a self-similar lexical structure that determines the stylistic features of a particular author. The novelty of the study is in application of fractal self-similarity to the analysis of the literary text "Grayling; or Murder Will Out" (1841) by the American writer William Gilmore Simms and two translations of the text into Russian made by I. Bernstein (1984) and M. Pavlycheva (2018). A freeware corpus analysis toolkit for concordancing and text analysis AntConc was used to find the ten most frequent lexemes in the original text. It is concluded that fractal self-similarity is exhibited in a certain identity of the lexical structure. The study of two translations showed that self-similarity is not always observed in the translated texts.

Keywords: fractal, fractal self-similarity, literary translation.

\author{
Сафина Зарема Миниаминовна \\ К.филол.н., доцент, Башкирский государственный \\ университет (2. Уфра) \\ safinazarema@mail.ru
}

Аннотация: В статье рассматривается фрактальное самоподобие в текстах оригинала и перевода. Новизна исследования связана с попыткой применения принципа фрактального самоподобия к анализу англоязычного оригинального текста Grayling; or Murder Will Out (1841) американского писателя Уильяма Гилмора Симмса и двух вариантов перевода, выполненных И.М. Бернштейн (1984) и М.Л. Павлычевой (2018). С помощью программы лингвостатистического анализа текста AntConc получена информация о десяти самых частотных лексемах в тексте оригинала. Сделан вывод 0 том, что фрактальное самоподобие проявляется в определенной идентичности лексической структуры текста. Результаты исследования двух переводов показали, что свойство самоподобия не всегда соблюдается в текстах перевода.

Ключевые слова: фрактал, фрактальное самоподобие, художественный перевод.

Феликс Хаусдорф, изучавшие непрерывные, но не дифференцируемые функции, предложили математическую трактовку фракталов [23]. Однако термин 'фрактал' был введен Б. Мандельбротом лишь в 1975 г. Данный термин образован от латинского причастия fractus, означающего «сломанный» или «раздробленный». Изучение фрактальных объектов заложило основу фрактальной геометрии, которую Б. Мандельброт назвал «новой геометрией природы» [20, р. 1]. Было замечено, что большинство объектов в природе являются фрактальными как в микроскопическом, так и в макроскопическом масштабе [13]. К природным объектам, в некоторой степени схожими с фракталами, относят облака, горные хребты, береговые линии, снежинки. Весьма большие различия объектов, относимых к классу фракталов, вызывают затруднения точного определения фрактала. По мнению Б. Мандельброта, «математические и естественные фракталы - это формы, шероховатость и фрагментация которых не стремятся к исчезновению, но остаются практически неизменными при постоянном увеличении масштаба и уточнении рассмотрения. Следовательно, структура каждой части является ключом ко всей структуре» $[21$, р. 4]. Выделяют следующие основные свойства геометрического фрактала [14]: сложная структура в сколь угодно малых масштабах; нерегулярность, которую нельзя описать традиционным языком евклидовой геометрии; самоподобие (или приближенное самоподобие); дробная (фрактальная) размерность, превосходя- 
щая топологическую размерность; рекурсивная процедура получения фрактала.

Таким образом, фрактал относится к классу геометрических фигур, которые при увеличении обнаруживают все более мелкие, но самоподобные структуры во всех масштабах. Эти фрактальные структуры являются результатом итерационных математических уравнений, способных выразить бесконечное количество деталей в кажущемся конечным пространстве. Как отмечает Н.Н. Белозерова, фрактал можно воспринимать как «модель вечноразвивающейся сущности, основанной на образовании самоподобных структур из каждой точки развития» $[1$, с. 103]. Хотя фракталы являются математической конструкцией, они встречаются как в природе, так и в человеческой деятельности. В целом, по мнению ряда исследователей, «фрактальная геометрия не есть «чистая» геометрическая теория. Это скорее концепция, новый взгляд на хорошо известные вещи, перестройка восприятия, заставляющая исследователя по новому видеть мир» [10, с. 12].

Фрактальная природа многих физических и социальных структур не подвергается теперь сомнению и язык не стал в этом случае исключением. Начиная со второй половины XX века стали изучаться самоподобные структуры на различных уровнях языка с применением приемов математического анализа (см., например, [18; 26]). Исследования, направленные на выявление таких параметров, как длина слова, длина текста, частота употребления языковых единиц, позволили чешскому лингвисту Л. Гребичеку выдвинуть гипотезу о фрактальной структуре естественных языков. Он отмечал, что «лингвистика нашла свой собственный путь к фракталам» [17, р. 86]. По утверждению Г. Парейона, основные характеристики фрактала, а именно: структурное самоподобие, неровная поверхность, фрактальная размерность, скалярная относительность, формальная последовательность, присущи и языку [22]. Отечественные учёные также проявляют интерес к возможности применения фрактальных свойств в исследованиях языка, рассматривая в своих работах вопросы фрактальной самоорганизации художественного дискурса [5], фрактальности дискурсивного пространства [6], фрактальной парадигмы метафоры [11]. Полагаем, что понятие фрактала, утверждающего самоподобие как одно из важнейших свойств развивающейся структуры, может быть перенесено в анализ текста в целом, а в настоящем исследовании - художественного текста, который условно можно рассматривать как некое структурное целое, распадающееся либо по семантическому, либо по формообразующему признаку на отдельные части - фракталы, каждый из которых представляет собой уменьшенную копию целого художественного произведения.

В данной работе предпринята попытка визуализации возможной фрактальной структуры художественных текстов, то есть возможной «регулярности» лексических структур, которые повторяются в разных масштабах таким образом, что фрагмент может быть подобен целому. В целях исследования проанализирован рассказ американского писателя XIX в. Уильяма Гилмора Симмса Grayling; or Murder Will Out [24]. Статистическая обработка текста производилась с помощью программы AntConc, представляющей собой свободно распространяемое мультиплатформенное средство лингвостатистического анализа текста. Программа AntConc используется для составления списков частотности и конкордансов, вычисления типичной дистрибуции, выявления ключевых слов и словосочетаний с заданным термином и т.п. Перед проведением статистических подсчетов анализируемый текст был отформатирован и конвертирован в текстовый файл, с которыми работает AntConc. Далее все слова были представлены в виде упорядоченного списка, таким образом, получена информация о частоте слов в тексте. Для дальнейшего анализа были отобраны 10 самых частотных лексем текста. Нами учитывались только слова знаменательных частей речи. Существительные единственного и множественного числа учитывались как одна лексема, например, man -> men, все части речи с общей основой также были включены в одну лексему, например, die -> death, dead. Результаты статистического анализа текста выглядят следующим образом (в скобках указано количество словоупотреблений): $\operatorname{man}(40)$, murder (30), feel (22), night (22), eye (21), mother (15), crime (14), live (14), die (12), heart (12). Таким образом, можно сделать вывод, что наблюдается фрактальное самоподобие ряда лексем в структуре анализируемого произведения. Датский лингвист Л. Ельмслев, работы которого, по мнению ряда исследователей, заложили основу рассмотрения языка с фрактальных позиций, полагал, что «текст возможно разложить на ограниченное число элементов, постоянно повторяющихся в различных комбинациях» [2, с. 206]. С точки зрения фрактальной геометрии фрактальный паттерн частотности является своеобразным индикатором стиля того или иного автора, о чем свидетельствуют работы, выполненные в этом направлении [12; 15]. В целом, «существование фрактальных словесных паттернов доказывает, что художественный текст это особый вид фрактала» [7, с. 918], самоподобный как на уровне одного текста, так и на уровне текстов одного автора. Если рассматривать текст как одномерное пространство, то пространственный паттерн вхождений любого слова образует фрактальное множество или просто фрактал. Кроме того, списки частотности также указывают на семантическую сложность текста.

Теория перевода, неразрывно связанная с лингвистикой, также претерпевает изменения, связанные с введением понятия фрактала в переводческий анализ текста. В рамках фрактального анализа предлагаются новые подходы к анализу перевода художественных текстов, 
основанные на соответствии текста перевода тексту оригинала с точки зрения количественных и структурных характеристик [16; 4]. В данной работе исследовано, каким образом фрактальная структура оригинала передана при переводе. Рассказ Grayling; or Murder Will Out имеет два варианта перевода, выполненные И.М. Бернштейн в 1984 г. (Грейлинг, или Убийство обнаруживается) [8] и М.Л. Павлычевой в 2018 г. (Грейлинг, или «Тайное станет явным») [9].

В текстах переводов были найдены соответствия 10 лексемам, указанным выше. Выяснилось, что при переводе всех лексем, за исключением murder, используется большое разнообразие лексических соответствий русского языка. В данной работе нами исследован перевод лексемы man. В переводе И. Бернштейн обнаружены следующие соответствия: человек (10 употреблений), люди (4), мужчина (3), он (2), джентльмен (2), незнакомец (1), тот (1), фермер (1), солдат (1), мо́лодцы (1). Статистика соответствий лексемы man в переводе М. Павлычевой выглядит следующим образом: человек (10 употреблений), люди (4), он (3), мужчина (2), mun (2), незнакомец (2), кто-нибудь (1), фермер (1), постоялец (1). Итак, И. Бернштейн использует 10 вариантов перевода лексемы man, а М. Павлычева - 9. В англо-русском словаре [19] обнаружены только 4 соответствия из предложенных переводчиками - человек, мужчина, солдат, люди. Таким образом, все остальные случаи перевода, в которых не наблюдается однозначного соответствия между единицами оригинала и перевода, могут служить доказательством нарушения свойства фрактального подобия между оригиналом и переводом. В ряде случаев в одном переводе прослеживается фрактальное подобие с оригиналом, а в другом переводе - нет, например, ... but Sparkman was a knowing man, who could turn his hand to a hundred things... - ...но Спаркмен был человек знающий и на все руки мастер... [8]. Но Спаркмен знал, что делает, у него все спорилось... [9].

Те случаи, когда позиции переводчиков относительно перевода слова man совпали, трактовались как проявления фрактального свойства подобия между двумя вариантами перевода. Например, The man had no weapons. - Незнакомец был безоружен [8]. Оружия незнакомец не имел [9]. "That's he! That must be the man!" - Эmо он! Не иначе как он! [8]. Это он! Это наверняка он! [9]. Такие примеры позволяют сделать предположение о фрактальной природе языка, имеющей универсальный характер, что проявляется, в том числе, в идентичности решений двух переводчиков.

Однако точное самоподобие не является основополагающим принципом фрактальной системы языка. Лингвистические объекты, признают исследователи, вообще не являются фракталами в строгом смысле [12, р. 7]. Так, одним из проявлений нелинейной фрактально- сти языка является использование разных слов для выражения одной и той же мысли. В нашем исследовании нелинейность можно проиллюстрировать примерами, в которых переводчики предлагают разные варианты перевода, например, «There was one man stayed with me last night» - Ночевал у меня давеча один джентльмен... [8] Вчера был только один постоялец... [9]. Б. Уорф, предвосхищая в 1940 г. идею фрактальной природы языка, писал, что «лингвистика требует точности отношения независимо от измерений» [25, р. 231]. Применительно к процессу перевода это может означать, что использование разных соответствий одного слова в двух переводах не должно влиять на смысловую составляющую оригинала. Однако наше исследование показывает, что в сложной языковой системе небольшие изменения некоторых параметров часто приводят к качественным различиям. Так, в следующем примере We can procure a warrant for searching the vessel after this man Macnab... - Выправим ордер на розыск этого самого Макнаба [8]. Мы можем проверить... там ли этот тun, Макнэб [9] второй вариант перевода представляется не совсем корректным, т.к. нарушается стилистическое подобие оригинала и перевода: английское man, в отличие от русского слова mun, не несет пренебрежительного оттенка значения.

Таким образом, из 40 случаев употребления лексемы man в обоих вариантах переведены 26 лексем, 14 лексем остались непереведенными. В следующем примере оба переводчика опустили при переводе данную лексему: I'm the only man in all that distance that's living on this road. - Я один живу у дороги, один на всю эту местность [8]. В округе у дороги живу только я... [9]. Полагаем, что отчасти данное обстоятельство может быть объяснено тем, что «язык предстает как неоднородная структура, а английский и русский языки являются разноструктурными языками, поэтому не все значения можно точно передать при переводе» [3, с. 780]. Таким образом, не всегда представляется возможным соблюдение принципа фрактального самоподобия в переводе художественного текста. Тем не менее, принимая во внимание данное свойство, переводчик имеет возможность рассматривать художественный текст как фрактальную структуру, построенную по принципу динамической симметрии.

Итак, в работе осуществлен анализ текстов оригинала и переводов с опорой на принцип фрактального самоподобия как основополагающего свойства фрактала. Теория фракталов представляет собой современный математический подход к изучению природных объектов и социальных систем, включая сложную динамическую систему языка. Материалом исследования послужил художественный текст Grayling; or Murder Will Out американского писателя У.Г. Симмса и два варианта перевода, выполненных И.М. Бернштейн и М.Л. Павлычевой. С помощью программы AntConc получена информация о частоте слов в тексте оригинала 
и отобраны 10 самых частотных лексем текста. Сделан вывод о фрактальном самоподобии при использовании автором лексических единиц в анализируемом тексте. Проведен статистический анализ с целью выявления фрактальной структуры оригинала в переводах. Фрактальный переводческий анализ основан на выявлении количественных и структурных соответствий единиц оригинала в текстах переводов. Выяснилось, что при переводе английских лексем оригинала используется большое разнообразие лексических соответствий русского языка. Так, при переводе лексемы man И.М. Бернштейн использовала 10 лексем, М.Л. Павлычева - 9, при этом только 4 из предложенных вариантов являются словарными соответствиями. В шести случа- ях мнения переводчиков относительно перевода слова man совпали, что трактуется нами как подтверждение свойства фрактального самоподобия. Однако исследование выявило, что данное свойство подчас нарушается в процессе перевода, что влечет за собой неточную интерпретацию художественного текста, представляющего собой сложную фрактальную систему. Полагаем, что используя принцип фрактального самоподобия, переводчик имеет шанс осуществить адекватный перевод художественного текста. Применение теории фракталов к анализу текстов представляет исследователю новый инструментарий для исследования стилевых особенностей конкретного автора и, в целом, для сопоставительного изучения разноструктурных языков.

\section{ЛИТЕРАТУРА}

1. Белозерова Н.Н. Линейность, гипертекстуальность, интертекстуальность, метафоризация и фрактальность: соотношение и взаимодействие в дискурсе (на материале стихотворений 0.Э. Мандельштама о Петербурге/Ленинграде) // Вестник Тюменского государственного университета. 2003. № 4. С. 102 - 113.

2. Ельмслев Л. Пролегомены к теории языка. М.: «КомКнига», 2006. 248 с.

3. Морозкина Е.А., Морозкин Ю.Н., Сафина 3.М. Фрактальные свойства глаголов движения в оригинале и переводе художественного текста // Вестник Башкирского университета. 2018. Т. 23. № 3. С. $777-782$.

4. Москальчук Г.Г., Бузаева Я.А. Самоподобие структуры текста как переводческая стратегия // Вестник ИГЛУ, 2013. № 3. С. 199 - 207.

5. Олизько Н.С. Интердискурсивность постмодернистского письма (на материале творчества Дж. Барта): монография. Челябинск: Челябинский государственный университет, 2009. 162 с.

6. Плотникова С.Н. Фрактальность дискурса как новое лингвистическое понятие // Вестник Иркутского государственного лингвистического университета. 2011. №3 (15). С. $126-134$.

7. Сафина 3.М., Морозкин Н.Н. Фрактальная рекурсивная система оригинала и перевода художественного текста // Вестник Башкирского университета. 2020. T. 25. № 4. С. $916-921$.

8. Симмс У.Г. Грейлинг, или Убийство обнаруживается (пер. И. Бернштейн) // Большое собрание мистических историй в одном томе. М.: Эксмо, 2015. С. 297 - 328.

9. Симмс У.Г. Грелинг, или «Тайное становится явным» (пер. М.Л. Павлычевой) // Вигвам и хижина. СПб.: Дмитрий Буланин, 2018. С. 27 - 55.

10. Тарасенко В.В. Логико-методологические аспекты концепции фрактала: автореферат диссертации ... кандидата философских наук: 09.00.08. М., 1998. 26 с.

11. Хахалова С.А. Метафорология: фрактальная парадигма // Вестник ИГлу, 2013. № 2. С. 79 - 85.

12. Andres J. On de Saussure's principle of linearity and visualization of language structures // Glottotheory. 2009. № 2/2. P. 1 - 14.

13. Barnsley M.F. Fractals everywhere. NY: Academic Press, 1993. 551 p.

14. Falconer K. Fractal geometry: mathematical foundations and applications. NY: John Wiley \& Sons, 1990. 288 p.

15. Gonçalves L.L., Gonçalves L.B. Fractal power law in literary English // Physica A. 2006. № 360. P. 557 - 575.

16. Gross A. Selected Elements from a Theory of Fractal Linguistics: Possible Implications for Machine Translation, Terminology Management, and Other NLP Applications // American Translators Association Series. Scientific and Technical Translation. Volume VI. 1993. P. 235 - 264.

17. Hrebíček L. Fractals in language // Journal of Quantitative Linguistics. 1 (1), 1994. P. 82-86.

18. LiW. Random Texts Exhibit Zipf's-Law-Like Word Frequency Distribution // URL: https://santafe.edu/research/results/working-papers/random-texts-exhibit-zipfslaw-like-word-frequency (дата обращения: 06.07.2021)

19. Lingvo Live — онлайн-словарь от ABBYY. URL: https://www.lingvolive.com/ru-ru. (дата обращения: 06.07.2021)

20. Mandelbrot B.B. Fractal geometry of nature. NY:W.H. Freeman and Company, 1983. 468 p.

21. Mandelbrot B.B. Fractal geometry: what is it, and what does it do? // Proceedings of the Royal Society of London - Series A. 1989. 423. P. 3 - 16.

22. Pareyon G. Fractal theory and language: the form of macrolinguistics // Symmetry: Art and Science. Journal of the International Society for the Interdisciplinary Study of Symmetry. Buenos Aires, 2007. P. $374-377$.

23. Pickover C.A. The math book. NY: Sterling, 2009.527 p.

24. Simms G.W. Grayling; or Murder Will Out // The Wigwam and the Cabin. NY: Redfield, 1856. P. 2 - 36.

25. Whorf B.L. Language, thought and reality. Cambridge: The M.I.T. Press, 1978. 278 p.

26. Zipf G.K. Human behavior and the principle of least effort. Cambridge: Addison-Wesley Press, Inc., 1949. 573 p. 